\title{
VOCABULÁRIO EXPRESSIVO DE CRIANÇAS ENTRE 22 E 36 MESES: ESTUDO EXPLORATÓRIO
}

\section{EXPRESSIVE VOCABULARY OF CHILDREN FROM TWENTY-TWO TO THIRTY-SIX MONTHS OF AGE: AN EXPLORATORY STUDY}

\author{
Márcia Regina Marcondes Pedromônico ${ }^{1}$ \\ Luciana Aparecida Affonso ${ }^{2}$ \\ Adriana Sañudo ${ }^{3}$
}

PEDROMÔNICO, M. R. M.; AFFONSO, L. A.; SAÑUDO, A. Vocabulário expressivo de crianças entre 22 e 36 meses: estudo exploratório. Rev. Bras. Cresc. Desenv. Hum., São Paulo, 12 (2), 2002.

\begin{abstract}
Resumo: O objetivo deste estudo foi descrever o vocabulário expressivo de uma amostra de crianças entre 22 e 36 meses, inseridas no Programa de Puericultura do Centro de Saúde de Vila Mariana (SP), por meio de entrevista com o cuidador primário. Para tanto, foram entrevistadas mães de 3() crianças, sendo 17 (57\%) do sexo masculino e 13 (43\%) do sexo feminino, e destas 15 entre 22 e 28 meses e 15 entre 29 e 36 meses. Utilizamos a Lista de Avaliação de Vocabulário Expressivo LAVE - (CAPOVILLA \& CAPOVILLA, 1997), sob a forma de entrevista com a mãe de cada criança. Foram calculadas medidas descritivas e empregada para tratamento estatístico a ANOVA. As crianças da amostra fadaram em média 195 palavras, sendo 3 crianças consideradas de risco para atraso de emissão. As crianças do sexo feminino produziram ao redor de 43 palavras e 2 palavras por frase a mais do que as crianças do sexo masculino. Verificamos que houve um acréscimo estatisticamente significativo no vocabulário de acordo com o aumento da faixa etária, independente do sexo. As categorias mais faladas por crianças da faixa etar^la estudada foram Pessoa.s, Partes do Corpo, Ações, Casa e Objetos. Com isto pôde-se concluir que é possível caracterizar o vocabulário e detectar crianças de risco para atrasos de emissão através de informações dos pais.
\end{abstract}

Palavras-chave: avaliação de linguagem; vocabulário expressivo; LAVE; triagem.

\section{INTRODUÇÃO}

O fato de pesquisas das últimas décadas apontarem para capacidades perceptuais e de aprendizagem no recém-nascido humano promoveu a ênfase no acompanhamento multiprofissional do desenvolvimento da criança, visando garantir a interferência neste processo quando da suspeita de atrasos ou desvios. Exemplo disto é a proposta enfatizando em vários países, inclusive no Brasil (PEREIRA et al., 1993; PEDROMÔNICO et al., 1998) do acompanhamento, por longo prazo, do desenvolvimento de recém-nascidos prematuros de peso inferior a 2000 gramas. As causas biológicas decorrentes de riscos pré e peri-natal são responsáveis por 10\% da etiologia dos diferentes níveis de gravidade do retardo mental (DSM IV, 1994). No entanto, as causas am-

1 Psicóloga. Doutora em Distúrbios da Comun icação Humana pela Universidade Federal dc São Paulo. Prot`essora Ad junta da Disciplina de Disturbios da Comunicação Humana. Chefe do Setor de Desenvolvimento do Comportamento da Intancia e da Adolescência da Disciplina de Distúrbios da Comunicação Humana da UNIFESP. Endereço para correspondência: Rua Afonso Celso, 575 apto 301. CEP: 04119-002. Vila Mariana São Paulo. E-mailmnarciadch.otor(ãepm.br

2 Fonoaudióloga. Especializada em Fonoaudiologia com ênfase em Psiquiatria Int'antil pela Universidade de São Paulo. Especializada em Distúrbios da Comunicação Humana pela UNIFESP.

3 Estatistica. Mestre em Estatistica pela Universidade de São Paulo. Professora da Disciplina de Bioestatistica da UNIFESP. 
bientais encontram-se entre aqueles fatores que podem restringir ou promover condições de manutenção da saúde do desenvolvimento da criança, mesmo na ausência de riscos biológicos (De ANDRACA et al., 1998). Além disto, RUTTER E SROUFE (2000) e SAMEROFF et al. (1987) afirmaram que a combinação de fatores de risco influencia mais nos atrasos no desenvolvimento do que um fator isolado, e que os fatores relacionados ao ambiente são mais determinantes na idade pré-escolar. Entretanto, em estudos de desenvolvimento é importante ressaltar que a capacidade de a criança enfrentar as adversidades, denominada de resiliência (ALVAREZ et al., 1998; RUTTER \& SROUFE, 2000), deve ser considerada quando se busca o efeito dos riscos conhecido ao longo do ciclo vital.

No acompanhamento do desenvolvimento da criança, o atraso motor é mais facilmente identificado, embora possua menor associação com o futuro do desenvolvimento da criança. O inverso ocorre com o desenvolvimento da linguagem, cuja identificação é mais difícil, porém de maior associação com o desempenho escolar, competência comportarnental e social futuras. Disto decorre a necessidade de aprimorar o conhecimento profissional nesta área.

Entre 22 e 36 meses de idade, as crianças apresentam uma “explosão” na aquisição do vocabulário e passam a organizar essas paavras em frases para conseguirem comunicar seus desejos e necessidades. Elas aprendem palavras que são nomes de coisas ou pessoas (bola, carro, cachorrinho, vovó, titia) e aquelas ligadas a relacionamentos sociais (você, mim, não, quer, sim, por favor, amo você, vá embora). Palavras, como os verbos, tendem a se desenvolver mais tarde. BEE (1996) afirmou que as primeiras frases de duas ou três palavras aparecem normalmente entre 18 e 27 meses. Para RESCORLA (1989), crianças normais de 02 anos de idade apresentam vocabulário expressivo de pelo menos 50 palavras e são capazes de formar combinações de duas ou três palavras.

Na idade pré-escolar escolar, o atraso de fala é uma das queixas mais freqüentes (BAX et al., 1980; LAW, 2001), sendo que esta pode ser uma manifestação comum entre as diferentes psicopatologias que acometem a criança. Por este motivo, entendemos que a identificação precoce deste sinal é fundamental. Uma das formas de identificação de atrasos de desenvolvimento do comportamento, estudadas e consideradas vantajosas por vários autores, são questionários preenchidos por pais (ARAM et al., 1984; GLASCOE et al.,1989; GLASCOE 1991; GLASCOE \& DWORKIN, 1995; DUTRA et al., 2002).
RESCORLA desenvolveu a IDS (Language Development Survey) objetivando identificar atrasos na população geral de crianças de 02 anos de idade. A LDS se propõe a pesquisar a linguagem emissiva, não sendo designada para acossar a linguagem receptiva, por ser considerada mais difícil a obtenção de dados acurados da mãe sobre a compreensão de seu filho. Tal questionário foi traduzido, adaptado, nornatizado e validado no Brasil por CAPOVILLA e CAPOVILLA (1997), e denominada de Lista de Avaliação do Vocabulário Expressivo (LAVE). Os estudos de RESCORLA (1989) e de CAPOVILLA e CAPOVILI A (1997) evidenciaram a capacidade do instrumento em diterenciar as crianças de dois anos com atrasos de emissão daquelas que adquiriram bem o vocabulário.

Com as premissas: 1 . atrasos de emissão estão associados ao futuro status de desenvolvimento; 2. atrasos de emissão podem indicar presença de uma psicopatologia; 3. atrasos de emissão se constituem num sinal possível de ser identificado aos dois anos por meio de informações do cuidador primário, neste estudo exploratório objetivamos descrever o vocabulário de uma amostra de crianças entre 22 e 36 meses, por meio de informação da mãe.

\section{METODOLOGIA}

Foram recrutadas crianças, com idades entre 22 e 36 meses, entre aquelas agendadas na Rotina do Programa de Puericultura do Centro de Saúde de Vila Mariana. Entre os meses de abril a Setembro de 2001, foi sorteado um dia da semana para a ocorrência da pesquisa, visando a possibilidade de participação das crianças de forma aleatória. Os critérios de seleção foram a faixa etária, o acompanhamento pediátrico no Programa de Puericultura e entrevistar a mãe sobre uma única criança filho da sua prole, para minimizar o viés da seleção da amostra. A amostra final constituiu-se de 30 crianças, 17 (57\%) do sexo masculino e 13 (43\%) do sexo feminino, 15 (50\%) da faixa etária de 22 a 28 meses e 15 (50\%) dos 29 aos 36 meses. Entre elas, 03 (10\%) eram prematuras e 27 (90\%) eram nascidas a tendo. Em relação às otites, encontramos 14 (47\%) sem quadros de otites e 16 (53\%) com quadros de otites.

Para caracterização dos antecedentes físicos e sócio-demográficos das crianças, foi utilizado o questionário proposto por RESCORLA (1987) e traduzido, adaptado, normatizado e validado no Brasil por CAPOVILLA e CAPOVILLA (1997), o qual antecede a lista de palavras - LAVE (Anexo I). 
47\% das famílias apresentavam uma renda mensal de até 2,5 salários mínimos, sendo que em $30 \%$ da amostra as famílias eram compostas de pelo menos 5 pessoas, ou seja, na maioria das famílias, a renda obtida era por volta de meio salário mínimo por pessoa. Além disso, $87 \%$ das crianças tinham menos de I mês de escolarização, 52\% das mães apresentaram de 04 ou menos anos de escolarização, 38\% estavam desempregadas e 28\% executavam trabalhos manuais não especializados (empregadas domésticas). Estes dados sugerem que a maioria das crianças e suas famílias viviam em precárias condições sócio-culturais.

A LAVE traduzida e adaptada por CAPOVILLA e CAPOVILLA (1997) da LDS (RESCORLA, 1987) foi o instrumento escolhido para investigar o vocabulário e detectar eventuais atrasos de emissão oral. Fizemos a opção por este instrumento de triagem em função dos dados de validação e contabilidade apontados por diferentes autores na literatura internacional e, no Brasil, por CAPOVILLA e CAPOVILLA(1997). ALAVE consta de uma lista com 307 palavras arranjadas em 14 categorias semânticas, escolhidas com base em estudos sobre o desenvolvimento lexical inicial e consideradas de alta freqüência (Anexo II). A mãe da criança deve assinalar aquelas palavras que sua criança fala espontaneamente. Neste estudo, utilizamos a forma de entrevista para o preenchimento, buscando evitar diferenças na aplicação quando a mãe era "não-leitor”, na sala de espera de consulta pediátrica. Para a classificação da criança com “suspeita” de atraso de emissão utilizamos os mesmos critérios da validação americana e do estudo brasileiro que registraram menos de 50 palavras ou ausência de combinação de 02 palavras. Encerrado o período de coleta de dados, foi computado o número de palavras produzidas registradas no protocolo de cada criança, e a seguir, os dados foram calculadas medidas descritivas do número total de palavras produzidas e número de palavras por frase, apresentadas em gráficos, sempre considerando as variáveis: sexo e faixa etária da criança. A Análise de Variância (ANOVA), com dois fatores fixos, foi utilizada para verificar o efeito de interação entre sexo e faixa etária no número total de palavras e número de palavras por frase. Foi calculada a proporção média do total de palavras produzidas pela amostra, por categoria, visando determinar qual classe semântica as crianças utilizaram mais frequentemente.

\section{RESULTADOS}

O número médio de palavras produzidas pelas crianças da amostra foi de 194,50 (£ 77,90) palavras. As crianças do sexo masculino produziram, em média, 175,65 ( \pm 82,18) palavras, enquanto as crianças do sexo feminino produziam, em média, 219,15 ( $\pm 67,07)$ palavras. O intervalo de confiança de $95 \%$ para o sexo masculino foi de $[136,58 ; 214,71]$ e para o sexo feminino foi de [182,69; 255,61] (Gráfico 1).

As crianças de 22 a 28 meses produziram, em média, 158,73 ( \pm 86,58) palavras, enquanto as crianças de 29 a 36 meses produziram, em média, 230,27 ( \pm 48,30) palavras. O intervalo de confiança para a faixa etária de 22 a 28 meses foi de [114,92; 202,55] e para 29 a 36 meses foi de [205,82; 254,71] (Gráfico 2).

O Gráfico 3 mostra a relação da média do número total de palavras produzidas em relação à faixa etária e ao sexo. Não existiu efeito de interação entre sexo e faixa etária $(p=0,149)$. Porém, pudemos verificar que houve um pequeno acréscimo no número total de palavras em relação ao sexo ( $p=0.059)$; quanto à faixa etária, as crianças mais velhas falaram em média 71 palavras a mais do que as mais novas, independente do sexo $(p=0.005)$.

As crianças do sexo masculino produziram $3,29( \pm 1,72)$ palavras por frase, enquanto as crianças do sexo feminino produziram 5,15 $( \pm 1,95)$. O intervalo de confiança para o sexo masculino foi de 12,$47 ; 4,11]$ e para o sexo feminino boi de [4 09; 6,21] apresentados no gráfico 04. As crianças de 22 a 28 meses produziram 3,53 ( $\pm 2,00)$ palavras por frase, enquanto que as crianças de 29 a 36 meses produziram 4,67 $( \pm 1,84)$ palavras por frase. $\mathrm{O}$ intervalo de confiança para a faixa etária de 22 a 28 meses foi de [2,47; 6,00] e para a faixa etária de 29 a 36 meses foi de [3,73; 5,60], apresentados no Gráfico 5.

O Gráfico 6 mostra a relação da média dc número de palavras por frase segundo o sexo faixa etária. Não existiu efeito de interação entre sexo e faixa etária $(\mathrm{p}=0,404)$. Porém, pudemos verificar que as meninas falaram aproximadamente 2 palavras a mais do que os meninos, independente da faixa etária ( $p=0.005)$ e que houve um pequeno acréscimo no número de palavras por frase em relação à faixa etária $(p=0.057)$.

Ainda a amostra foi estudada segundo a frequência de uso de cada uma das 14 categorias. Em função de na listagem o número de palavras em cada categoria não ser o mesmo, calculamos a proporção da distribuição de palavras por categoria e a seguir a proporção média de uso, considerando o total de crianças da amostra. Na tabela I estão apresentadas as proporções médias de uso de cada categoria pelas crianças da amostra, dispostas em ordem decrescente de freqüência. 


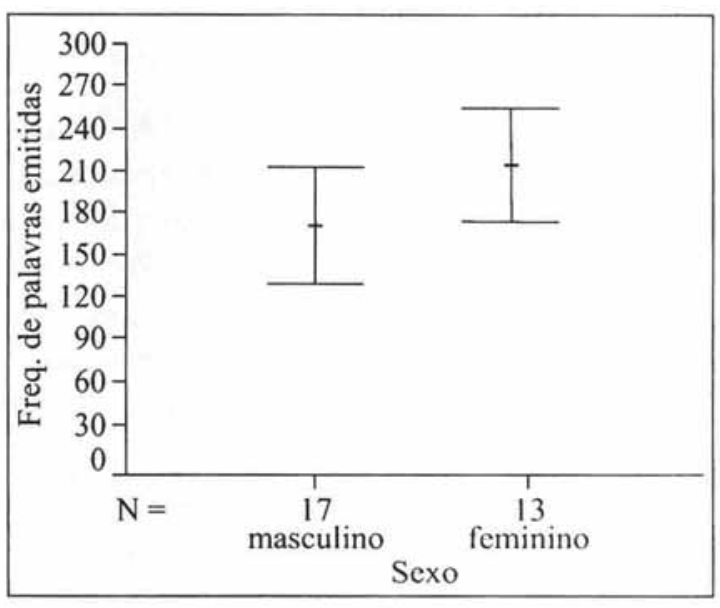

Gráfico 1: Freqüência de palavras por sexo (média e Desvio padrão).

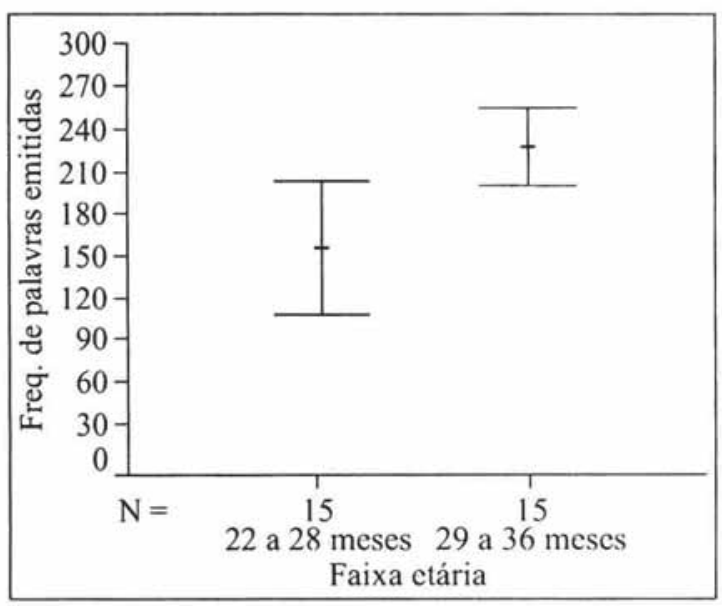

Gráfico 2: Freqüência de palavras por faixa etária (média e desvio padrão).

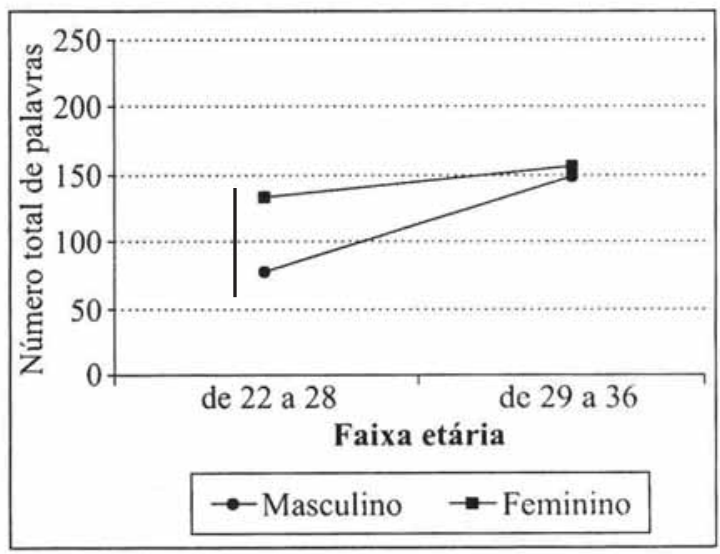

Gráfico 3: Média do número total de palavras produzidas em relação à faixa etária e ao sexo

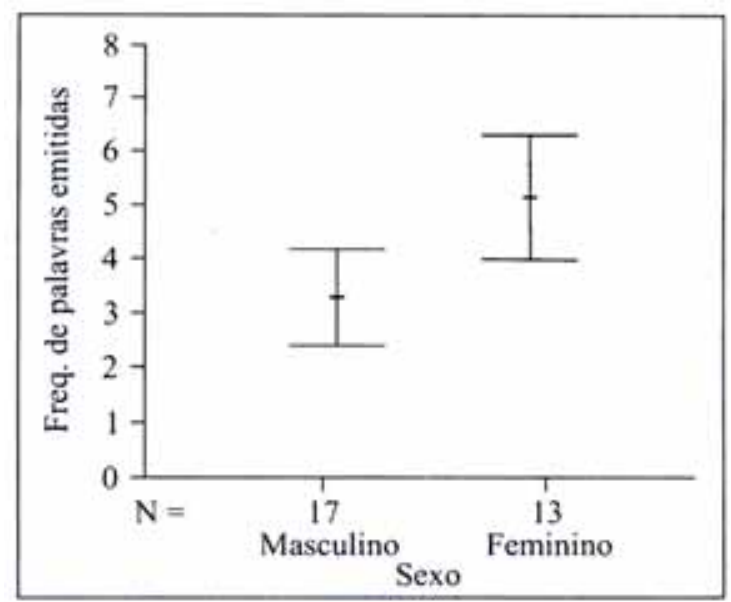

Gráfico 4: Freq. de palavras como função dc sexo (média e desvio padrão)

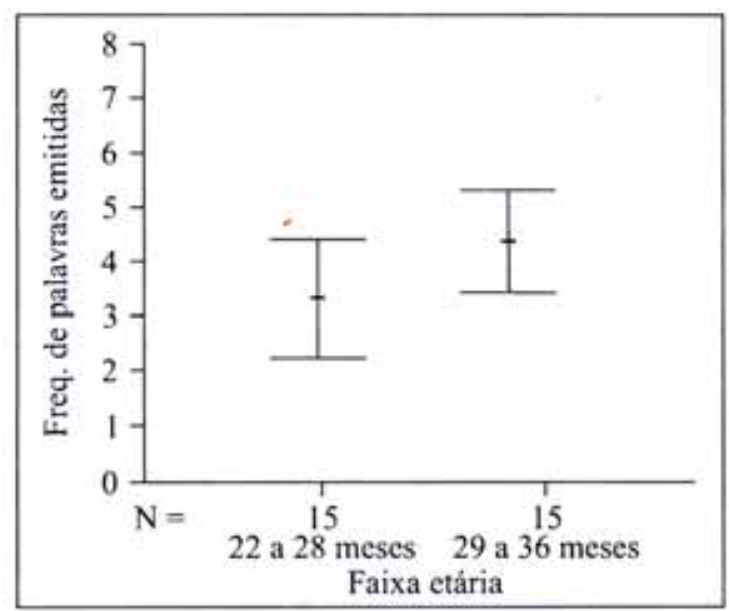

Gráfico 5: Freq. de palavras como função de faixa etária (média e desvio padrão)

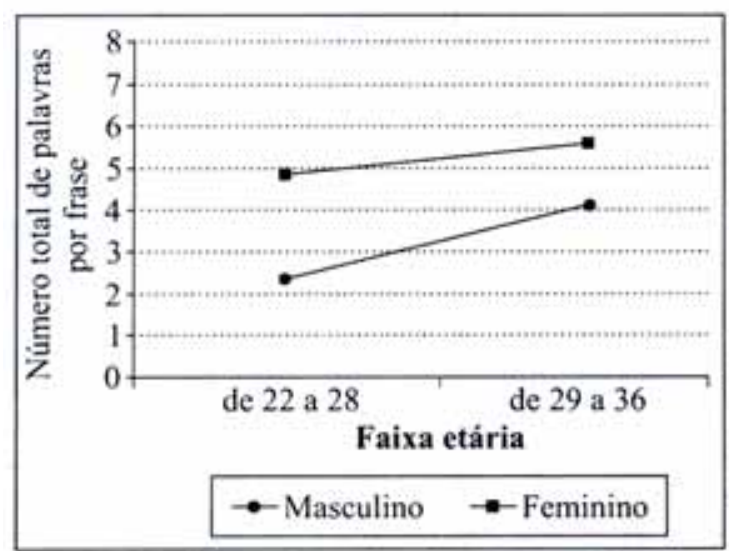

Gráfico 6: Média do número de palavras produzidas por frase em relação à faixa etária e ao sexo 
Comparando as proporções médias, encontramos como a categoria mais freqüente Pessoas e a menos freqüente Lugares. Quando comparamos os intervalos de confiança, entre esta categoria e Partes do Corpo, Ações, Casa e Objetos, não ocorreram diferenças estatisticamente sendo que os intervalos se sobrepõem e desta forma podemos considerar ser estas as quatro categorias apareceram como as mais frequentes na amostra.

\section{COMENTÁRIOS}

O número de palavras produzidas pela amostra foi de 195 palavras. Considerando o critério proposto por RESCORLA (1989) e CAPOVILLA e CAPOVILLA (1997), encontramos que 03 (10\%) crianças da amostra eram de risco para atraso de linguagem expressiva. Uma das

Tabela 1: Ordern decrescente de freqüência de palavras produzidas por categoria

$\begin{array}{lcc}\text { Gategorias } & \text { Properçã Média } & \text { 95\% } \\ \text { Pestos } & \text { [73\%; } & \text { [73\%] } \\ \text { Partes do Corpo } & 71 \% & {[60 \% ; 82 \%]} \\ \text { Ações } & 68 \% & {[59 \% ; 78 \%]} \\ \text { Casa } & 67 \% & {[56 \% ; 78 \%]} \\ \text { Objetos } & 65 \% & {[53 \% ; 77 \%]} \\ \text { Comida } & 63 \% & {[55 \% ; 72 \%]} \\ \text { Veículo } & 63 \% & {[52 \% ; 75 \%]} \\ \text { Roupas } & 63 \% & {[51 \% ; 74 \%]} \\ \text { Modificadores } & 62 \% & {[49 \% ; 74 \%]} \\ \text { Outros } & 61 \% & {[51 \% ; 73 \%]} \\ \text { Ambiente } & 57 \% & {[47 \% ; 68 \%]} \\ \text { Animais } & 44 \% & {[41 \% ; 62 \%]} \\ \text { Brinquedo } & 41 \% & {[135 \% ; 54 \%]}\end{array}$

crianças falava apenas 04 palavras e as outras duas não formavam frases. O estudo de BAX et al. (1980) detectou $17 \%$ de prevalência de problemas de linguagem em crianças de 02 anos e 12\% para crianças de 03 anos, em uma amostra bastante grande. Sob esta referência, nossa amostra pareceu ter comportamento semelhante. No entanto, consideramos este percentual alto e lembramos que o tamanho da amostra pode ter interferido neste percentual. Vale ainda ressaltar, que os dados como o da renda familiar, tamanho da familia, escolaridade e ocupação materna puderam determinar esta amostra como sendo, predominantemente, de classe social baixa média-baixa, o que vem sendo considerado como condiçao de risco para o desenvolvimento das crianças em função dos desdobramentos decorrentes desta condição tais como baixa expectativa, ambientes pou- co enriquecidos e dificuldade de transmissão de experiências entre os adultos e as crianças (De ANDRACA et al., 1998; RAMEY \& RAMEY, 1998). Em nosso estudo, os dados sobre a ocupação materna indicaram que 38\% das mães estavam desempregadas. Este fato pode ser um fator de risco quanto à relação com seus filhos, primeiro em função do "grau de satisfação com a vida" e segundo pela preocupação em adquirir uma forma de contribuir com a renda familiar, o que pode reduzir o investimento na criança, dificultando o acesso da mesma à exploração do ambiente. Além disto, 21\% das mães deste estudo tinham quatro ou menos anos de escolaridade, o que é referido pela UNICEF (2001) como escolarização precária e de alto risco para o desenvolvimento global das crianças, e em especial para o desenvolvimento da linguagem.

Quando comparamos o número médio de palavras produzidas pela amostra em relação ao sexo, encontramos que as crianças do sexo feminino produzem 43 palavras a mais do que as crianças do sexo masculino, o que indica que as meninas, independentemente da faixa etária, falam mais palavras na idade estudada, achado este concordante com os de RESCORLA (1989); DALE (1991); ROBERTS et al. (1999). Quanto ao número de palavras produzidas por frase, as meninas produziram aproximadamente duas palavras a mais do que os meninos. BEE (1996) referiu que as diferenças entre os sexos aparecem em habilidades específicas, o que pode ter sido evidenciado neste estudo sobre a área de linguagem emissiva.

Quando comparamos o número médio de palavras produzidas pela amostra em relação à faixa etária, encontramos que as crianças de 29 a 36 meses de idade produziram 71 palavras a mais do que as crianças de 22 a 28 meses, indicando que houve um acréscimo estatisticamente significativo no número de palavras de acordo com o aumento da idade. $\mathrm{O}$ mesmo ocorreu em relação ao número de palavras por frase. Estes achados, referidos por muitos autores (BAX et al., 1980; BATES et al., 1994; REZNICK \& GOLDFIELD, 1994; CAPOVILLA \& CAPOVILLA, 1997; ROBERTS et al., 1999), possivelmente se relacionam ao fato de as crianças, conforme ficam mais velhas, ampliarem a consciência de si como efetivos comunicadores através da linguagem oral, além do acréscimo qualitativo em suas estruturas mentais.

Com relação à categoria mais freqüente, as crianças da amostra falaram mais as palavras da categoria Pessoas, Partes do Corpo, Ações, Casa e Objetos. Observando as palavras incluídas em cada uma dessas categorias, é possível 
identificar o quanto, nas idades estudadas, o ambiente humano-familiar da criança possui maior valência afetiva. A categoria Pessoas incluiu palavras como mamão, papai, vovó, vovô que, na prática clínica, as mães sempre relatam ser as primeiras palavras do vocabulário infantil. A categoria Partes do Corpo também apresentou palavras comuns, já que as mães desde cedo nomeiam as partes do corpo durante o banho, a alimentação e a troca. A categoria Ações envolveu palavras como dar, querer, comer, dormir, fazer que são os verbos mais comuns nesta idade, pois são aqueles que permitem as primeiras justaposições de palavras. As categorias Casa e Objetos apresentaram palavras como cama, faca, copo, TV, escova, chave que são de uso diário das famílias. É compreensível que as categorias mais faladas pelas crianças da nossa amostra tenham sido estas, pois são palavras de alta freqüência no início da aquisição lexical, já que estas são as palavras que fazem parte das experiências de troca da criança com a mãe. Quanto à categoria menos freqüente Lugares - encontramos relação com o estudo brasileiro de BEFI-LOPES e GALEA (2000) que referiu que as crianças de sua amostra apresentaram pior desempenho nesta categoria.

Com base neste estudo exploratório, acreditamos que a LAVE seja um instrumento útil e eficaz para detectar crianças com atraso de emissão; além disto, atende critérios básicos para um instrumento de triagem: ser de baixo custo, de rápida e fácil aplicação. Quando a escolaridade materna for considerada precária (igual ou inferior a 4 anos de estudo completos), sugerimos que a aplicação da LAVE seja feita sob a forma de entrevista.

Partindo destes dados, pretendemos continuar a investigação sobre a aplicabilidade da LAVE na triagem de atrasos de emissão, aumentando o número de crianças da amostra com as seguintes hipóteses de estudo:
- em diferentes condições sócio-culturais as diferenças no número de palavras entre meninos e meninas se mantém?

- o sexo poderia interagir com a faixa etária e, essas variaveis juntas, poderiam influenciar no número total de palavras produzidas e no número de palavras por frase em diferentes condições sócio-culturais?

- a frequência de uso das categorias se modificaria com aumento da amostra ou com diferenças do ambiente de origem das crianças?

- a escolarização pode se constituir em fator de proteção para crianças de baixa renda?

Consideramos de extrema importância a detecção precoce de crianças de risco e também dos fatores que interferem nesta condição de atraso, para termos a possibilidade de referir para uma avaliação completa e interferir, com um programa eficiente. Esta é uma das formas de garantir melhores condições de desenvolvimento infantil, promovendo o desenvolvimento típico em todos os seus aspectos, principalmente no que diz respeito à Linguagem.

\section{CONCLUSÕES}

Na amostra de crianças de 22 a 36 meses atendidas no Programa de Puericultura do Centro de Saúde Vila Mariana: as meninas falam mais palavras e mais palavras por frase do que os meninos; as crianças mais velhas falam mais palavras e mais palavras por frase do que as mais novas; as categorias mais freqüentes foram Pessoas, Partes do Corpo, Ações, Casa e Objetos e a menos frequente foi Lugares. As mães, independente de sua escolarização, são boas informantes sobre o desenvolvimento do vocabulário de seus filhos.

\begin{abstract}
This study aimed at describing lhe vocabulary of children from twenty-two to thirtysix months of age, inserted into lhe child care program of the Health Center of Vila Mariana - São Paulo. We interviewed lhe mothers of 30 children, 17 (57^ó) mate and 13 (43\%) female; 15 were between 22 and 28 months of age and 15 were between 29 and 36 months of age. We used lhe Expressive VocabularyAssessmer^ltChecklist (CAPOVILLA \& CAPOVILLA, 1997). We calculated the descriptive measures and used ANO $\wedge$ VA for the statistical treatment. The results showed that children around two years of aKe speak an average of ! 95 words. The girls spoke 43 words more than the boys and two words more per sentence. We verified that as age increased, the number of words used and the number of words per sentence also increased in both sexes. The categories that were most spoken by the children were names of people, body parts, actions, house and objects. We concluded that it is possible to characterize children's vocabulary and to detect children with utterance delay through the parents' information.
\end{abstract}

Key-words: language assessment; expressive vocabulary; LDS; screening. 


\section{REFERÊNCIAS BIBLIOGRÁFICAS}

AMERICAN PSYCHIATRIC ASSOCIATION DIAGNOSTIC AND STATISTICAL MANUAL OF MENTAL DISORDERS.4 $4^{a}$ edition. Washington, DC: 1994.

ARAM, D. M.; EKELMAN, B.L.; NATION, J.E. Preschoolers with language disorders: 10 years later. J. Speech Hear Res., 27: 232244,1984.

BATES, E.; MARCHMAN, V; THAL, D.; FENSON, L.; DALE, RS.; REZNICK, J.S. et al. Developmental and stylistic variation in the composition of early vocabulary. J. Child Lang, 21: 85- 123, 1994.

BAX, M; HART, H.;JENKINS, S. Assessment of speech and language development in the young child. Pediatrichcs, 66(3): 35()-354, 1980.

BEE, H. A criança em desenvolvirmento. $7^{\mathrm{a}}$ ed. Porto Alegre: Artes Médicas, 1996.

BEFI-L OPES, D. M.; GALEA, D. E. S. Análise do desempenho lexical em crianças com alterações no desenvolvimento da linguagem. PróFono, 12 (2): 31 -37. 2000.

CAPOVILLA, F. C.; CAPOVILLA, A. G. S. Desenvolvimento lingüistico na criança dos dois aos seis anos: tradução e estandardização do peabody picture vocabulary test de Dunn \& Dunn, e da language development survey de Rescorla. Ciência Cognitiva. Teoria, Pesquisa e Aplicação, 1(1): 353-380, 1997.

DALE, $P$. The validity of a parent report measure of vocabulary and syntax at 24 months. J Speech Hear Res, 34: 565-571, 1991.

De ANDRACA, I.; PINO, P; LA PARRA, A.; RIVERA, F.; CASTILLO, M. Factores de riesgo para el desarrollo psicomotor en lactantes nacidos en óptimas condiciones biológicas. Rev Saúde Pública, 32 (2): 138-147, 1998.

DUTRA, M.D.S.; DAN, I.B.; ALMEIDA, L.M.S.; PEDROMÔNICO, M.R.M. Linguagem expressiva: estudo em cnanças entre 22 e 35 meses. In: Anais. São Paulo: $17^{\circ}$ Encontro Intemacional deAudiologia: 2002. p.97.

GLASCO, E. F. P. Can clinical judgment detect children with speech-language problems? Pediaitrics, 87(3): 317-321,1991.

GLASGOE, F. R; ALTEMEIER, W. A.; MACLEAN, W. E. The importance of parents' concerns about their child's development. AJDC, 143: 955-958, 1989. GLASCOE, F. P.; DWORKIN, R. H. The role of parents in the detection of developmental and behavioral problems. Pediatrics, 95(ó): 829-X36, 1995.
LAW, J. Identificação precoce dos distúrbios da linguagem na criança. Rio de Janeiro: Revinter, 2001. p.21-41.

ALVAREZ, M. A. S.; MORAES, M. C.; RABINOVICH, E. P. Rev Bras Cresc Desenv Hum, 8(1/2): 70-74, 1998.

PEDROMÔNICO, M. R. M.; AZEVEDO, M. F.; KOPEIMAN, B. I. Recém-nascidos pré-termo internados em unidade de terapia intensiva: desenvolvimento da conduta interativa no primeiro ano de vida. J Pedriatr., 74(4): 284-290, 1998.

PEREIRA, M. R.; PERISSINOTO, J.; CHIARI, B. M. Bebê pré-termo: algumas consideracões sobre o desenvolvimento da linguagem à partir da observação fonoaudiológica. Pró-Fono, 5(2): 2932, 1993.

RAMEY, C. T.; RAMEY, S. L. Prevention of intellectual disabilities: early interventions to improve cognitive development. Prev Med, 27: 224-232, 1993.

RESCORLA, L. The language development survey: a screening tool for delayed language in toddlers. J Speech HearDisord, 54: 587-599, 1999.

REZNICK, J. S.; GOLDFIELD, B. A. Diary vs. representative checklist assessment of productive vocabulary. J. Child Lang, 21: 465-472, 1994.

ROBERTS, J. E.; BURCHINA, L. M.; DURHAM, M. Parent's report of vocabulary and grammatical development of african american preescholers: child and environmental associations. Child Dev, 70(1): 92-106, 1999.

RUTTER, M.; SROUFE, L. A. Development child Psychopathology. ConceptsAnd Challenges. Development and Psychopathology, 12: 265-296, 2000.

SAMEROFF, A. J.; SEIFER, R.; BAROCAS, R.; ZAX, M.; GREENSPAN, S. Intelligence quotient scores of 4-year-old children: social-environmental risk factors. Pediatrics, 79 (3): 343-350, 1987.

UNICEF. Situação da Infância Brasileira 2001 [online]. UNICEF; 2001. Disponível em: http:/ / www.ünicef.org/brazil/sib200 1 /index.htm

Recebido em 15/05/2002

Modificado em 30/07/2002 Aprovado em 15/08/2002 
ANEXO I

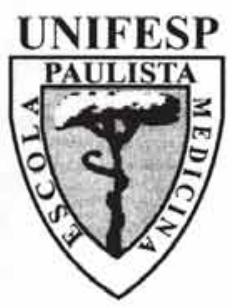

Setor de Desenvolvimento do Comportamento da Infância e Adolescência Coordenação: Profa. Dra. Márcia Regina Marcondes Pedromônico Disciplina de Distúrbios da Comunicą̧ão Humana Universidade Federal de São Paulo - Escola Paulista de Medicina

Lista de Avaliação de Vocabulário Expressivo - LAVE

Tradução e adaptação de Capovilla, Capovilla (1997)

Data: ___ _ _ _ Seu nome:

Parentesco com a criança:__ Nome da criança:

Data de nascimento: Sexo:

\begin{tabular}{|l|l|l|}
\cline { 2 - 3 } \multicolumn{1}{c|}{} & \multicolumn{1}{c|}{ MAE } & \\
\hline Nome & & \\
\hline Endereço & & \\
\hline Telefone & & \\
\hline Data Nascimento & & \\
\hline Estado Civil & & $\begin{array}{l}\text { Não empregado ( ) } \\
\text { Empregado Tempo Parcial ( ) } \\
\text { Empregado Tempo Integral ( ) }\end{array}$ \\
\hline Escolaridade & Não empregado ( ) & \\
\hline Emprego & Empregado Tempo Parcial ( ) & \\
\hline Ocupação & - & \\
\hline
\end{tabular}

Renda Familiar: R\$

Escreva o sexo e idade de outras crianças da família:

Alguém em sua família apresentou atraso para a aprender a falar?( )não( )sim. quem?

Antecedentes Mórbidos:

Doenças Crônicas da Criança

Peso ao Nascimento_ gr.Tipo de Parto

dias Intercorrência Peri-natal ( )não ( )sim Quais?

Sua criança é prematura?

De quantas semanas

Quantas infecções de ouvido sua criança teve durante os dois primeiros anos de vida?

Outras infecções? Quais?

Sua criança é cuidada por babá?

Quantas horas por semana?

Sua criança já foi ao fonoaudiólogo?

Qual o motivo?

Sua criança já foi ao psicólogo?Qual o motivo?

Sua criança tem __ anos e___ meses de idade. Ela já tem meses de escolarização (não incluir os periodos de férias) e forma frases com até: $\left(\_\right)$uma palavra $\left(\_\right.$) duas palavras $\left(\_\right)$três palavras $\left(\_\right)$quatro palavras $\left(\_\right.$) cinco palavras $\left(\_\right)$ seis palavras ( $\_$) sete ou mais palavras

Além da escola, sua criança tem aulas de algum outro tipo? (_) natação (_) balé (_) música (_) linguas (_) creche (_) outros

Se sim, em que sentido?

Por favor, escreva algumas outras palavras que sua criança usa aqui:

Ela combina duas ou mais palavras em frases? (ex.: mais bolo, bebê está chorando) ( ) Sim ( ) Não Por favor, escreva abaixo TRES das frases mais longas ou mais bem construidas que sua criança tenha falado: 


\section{ANEXO II}

Por favor, na lista faça um risco sobre cada palavra que sua criança fala. Você pode incluir palavras que a criança não pronuncia claramente. Não inclua palavras que sua criança pode compreender, mas não fala. Também não inclua palavras que sua criança repete depois de você por imitação, mas não fala espontaneamente.

\begin{tabular}{|c|c|c|c|c|c|c|}
\hline COMIDAS & ETE & Olho & \begin{tabular}{|l} 
Fazer \\
Fechar \\
Ir \\
Jantar \\
Jogar \\
Lavar \\
Ler \\
Mostrar \\
Olhar \\
Parar \\
Passear \\
Pegar \\
Pular \\
Querer \\
Sair \\
Sentar \\
Ter \\
Tomar \\
Tossir \\
Trazer \\
Ver \\
Vir \\
Xixi \\
\end{tabular} & \multirow{8}{*}{$\begin{array}{l}\text { Sofá } \\
\text { Telefone } \\
\text { Tigela } \\
\text { Toalha } \\
\text { Travesseiro } \\
\text { TV } \\
\text { Xícara } \\
\text { OBJETOS }\end{array}$} & & \\
\hline \multirow{44}{*}{$\begin{array}{l}\text { Água } \\
\text { Bala } \\
\text { Banana } \\
\text { Bcbida } \\
\text { Biscoito } \\
\text { Bolacha } \\
\text { Bolinho } \\
\text { Bolo } \\
\text { Cachorro- } \\
\text { quente } \\
\text { Café } \\
\text { Carne } \\
\text { Chá } \\
\text { Chiclete } \\
\text { Comida } \\
\text { Doce } \\
\text { Hambúrgucr } \\
\text { Laranja } \\
\text { Lcite } \\
\text { Maçã } \\
\text { Macarrão } \\
\text { Manteiga } \\
\text { Ovo } \\
\text { Pão } \\
\text { Pizza } \\
\text { Qucijo } \\
\text { Refrigerante } \\
\text { Sopa } \\
\text { Sorvete } \\
\text { Suco } \\
\text { Sucrilhos } \\
\text { Torrada } \\
\text { Uva } \\
\text { BRINQUE- } \\
\text { DOS } \\
\text { Balanço } \\
\text { Balão } \\
\text { Bola } \\
\text { Bolinha de } \\
\text { sabão } \\
\text { Boneca } \\
\text { Escorregador } \\
\text { Lápis de cor } \\
\text { Lego } \\
\text { Livro } \\
\text { Presente } \\
\text { Ursinho de } \\
\end{array}$} & \multirow{11}{*}{$\begin{array}{l}\text { Árvore } \\
\text { Calçada } \\
\text { Casa } \\
\text { Chuva } \\
\text { Estrela } \\
\text { Flor } \\
\text { Lua } \\
\text { Neve } \\
\text { Rua } \\
\text { Sol } \\
\text { ANIMAIS }\end{array}$} & & \multirow{21}{*}{$\begin{array}{l}\text { Ir } \\
\text { Jantar } \\
\text { Jogar } \\
\text { Lavar } \\
\text { Ler } \\
\text { Mostrar } \\
\text { Olhar } \\
\text { Parar } \\
\text { Passear } \\
\text { Pegar } \\
\text { Pular } \\
\text { Querer } \\
\text { Sair } \\
\text { Sentar } \\
\text { Ter } \\
\text { Tomar } \\
\text { Tossir } \\
\text { Trazer } \\
\text { Ver } \\
\text { Vir } \\
\text { Xixi }\end{array}$} & & \multirow{11}{*}{$\begin{array}{l}\text { Chapéu } \\
\text { Chinelo } \\
\text { Cinto } \\
\text { Cueca/calcinha } \\
\text { Fralda } \\
\text { Jaqueta } \\
\text { Meias } \\
\text { Pijama } \\
\text { Sapato } \\
\text { Short } \\
\text { Tênis } \\
\text { Vestido } \\
\end{array}$} & \\
\hline & & \multirow{6}{*}{$\begin{array}{l}\text { Pé } \\
\text { Peito } \\
\text { Perna } \\
\text { Pescoço } \\
\text { Qucixo } \\
\text { Rosto } \\
\end{array}$} & & & & \\
\hline & & & & & & \\
\hline & & & & & & \\
\hline & & & & & & \\
\hline & & & & & & \\
\hline & & & & & & \\
\hline & & LUGARES & & \multirow{14}{*}{$\begin{array}{l}\text { Caderno } \\
\text { Caneta } \\
\text { Chave } \\
\text { Dinheiro } \\
\text { Escova } \\
\text { Escova de } \\
\text { dente } \\
\text { Guarda-chuva } \\
\text { Lápis } \\
\text { Lenço } \\
\text { Mochila } \\
\text { Moeda } \\
\text { Óculos } \\
\text { Papel } \\
\text { Pente }\end{array}$} & & \\
\hline & & \multirow{9}{*}{\begin{tabular}{|l|} 
Cantina \\
Escola \\
Hospital \\
Igreja \\
Loja \\
McDonald's \\
Parque \\
Quarto \\
Zoológico \\
\end{tabular}} & & & & \\
\hline & & & & & & $\begin{array}{l}\text { Mau } \\
\text { Meu } \\
\text { Molhado } \\
\text { Pequeno } \\
\text { Pesado } \\
\text { Preto } \\
\text { Que } \\
\text { Quebrado } \\
\text { Quente } \\
\text { Sujo } \\
\text { Vermelho }\end{array}$ \\
\hline & & & & & & \multirow{34}{*}{$\begin{array}{l}\text { OUTROS } \\
\text { (palavrões, } \\
\text { ex.: chato) } \\
\text { A,B,C, etc. } \\
\text { Aqui } \\
\text { Au au } \\
\text { Bem vindo } \\
\text { Boa noite } \\
\text { Comigo } \\
\text { Desculpc } \\
\text { Desligado } \\
\text { Em } \\
\text { Embaixo } \\
\text { Fora } \\
\text { Longe } \\
\text { Gostoso } \\
\text { Lá } \\
\text { Ligado } \\
\text { Me } \\
\text { Miau } \\
\text { Mim } \\
\text { Não } \\
\text { O que } \\
\text { Obrigado } \\
\text { Oi } \\
\text { Onde } \\
\text { Por favor } \\
\text { Por que } \\
\text { Quieto } \\
\text { Sim } \\
\text { Tchau } \\
\text { Você } \\
\text { Xuxa } \\
1,2,3 \text {, etc. }\end{array}$} \\
\hline & \multirow{20}{*}{$\begin{array}{l}\text { Abelha } \\
\text { Cachorro } \\
\text { Cavalo } \\
\text { Cobra } \\
\text { Coclho } \\
\text { Elefante } \\
\text { Filhote } \\
\text { Galinha } \\
\text { Gato } \\
\text { Macaco } \\
\text { Mosquito } \\
\text { Pássaro } \\
\text { Pato } \\
\text { Peixe } \\
\text { Peru } \\
\text { Porco } \\
\text { Sapo } \\
\text { Tartaruga } \\
\text { Tigre } \\
\text { Urso } \\
\text { Vaca }\end{array}$} & & & & & \\
\hline & & & & & \multirow{10}{*}{$\begin{array}{l}\text { Avião } \\
\text { Barco } \\
\text { Bicicleta } \\
\text { Caminhão } \\
\text { Carrinho } \\
\text { Carro } \\
\text { Moto } \\
\text { Ônibus } \\
\text { Patins } \\
\text { Trem } \\
\end{array}$} & \\
\hline & & & & & & \\
\hline & & & & & & \\
\hline & & & & & & \\
\hline & & & & & & \\
\hline & & & & & & \\
\hline & & & & & & \\
\hline & & & & & & \\
\hline & & Ajudar & & & & \\
\hline & & Almoçar & CASA & & & \\
\hline & & & \multirow{7}{*}{$\begin{array}{l}\text { Berço } \\
\text { Cadeira } \\
\text { Cama } \\
\text { Chão } \\
\text { Chuveiro } \\
\text { Cobertor } \\
\text { Colher }\end{array}$} & \multirow{15}{*}{$\begin{array}{l}\text { (animal de } \\
\text { estimação) } \\
\text { (seu próprio } \\
\text { nome/apelido) } \\
\text { bebê (ou) nenê } \\
\text { homem } \\
\text { mãe } \\
\text { médico } \\
\text { menina } \\
\text { menino } \\
\text { mulher } \\
\text { pai (ou) papai } \\
\text { tia } \\
\text { tio } \\
\text { vó (ou) vovó } \\
\text { vô (ou) vovô }\end{array}$} & & \\
\hline & & & & & & \\
\hline & & Arrt & & & & \\
\hline & & Banho & & & & \\
\hline & & & & & & \\
\hline & & & & & & \\
\hline & & & & & & \\
\hline & & & & & & \\
\hline & & & & & & \\
\hline & & & & & & \\
\hline & & Cantar & & & & \\
\hline & \multirow{11}{*}{\multicolumn{2}{|c|}{\begin{tabular}{l|l} 
Barriga & Chutar \\
Boca & Cócega \\
Bochecha & Cocô \\
Braço & Comer \\
Bumbum & Conseg \\
Cabelo & Correr \\
Cotovelo & Cortar \\
Dedão & Dançar \\
Dedo & Dar \\
Dentes & Descan \\
Joelho & Dormir \\
-Mão & Empurr \\
Nariz & Escond \\
& cscondo
\end{tabular}}} & & & & \\
\hline & & & & & & \\
\hline & & & & & & \\
\hline & & & & & & \\
\hline & & & & & & \\
\hline & & & & & & \\
\hline & & & & & & \\
\hline & & & & & & \\
\hline & & & & & & \\
\hline & & & & & & \\
\hline & & & & & & \\
\hline
\end{tabular}

